Federal Reserve Bank of Minneapolis

Research Department

\title{
POLICY COOPERATION AMONG BENEVOLENT \\ GOVERNMENTS MAY BE UNDESIRABLE
}

\author{
Patrick J. Kehoe* \\ Working Paper 373 \\ October 1987
}

NOT FOR DISTRIBUTION

WITHOUT AUTHOR APPROVAL

\section{ABSTRACT}

This paper presents a simple counterexample to the belief that policy cooperation among benevolent governments is desirable. It also explains circumstances under which such counterexamples are possible and relates them to the literature on time inconsistency.

*Federal Reserve Bank of Minneapolis and University of Minnesota.

The views expressed herein are those of the author and not necessarily those of the Federal Reserve Bank of Minneapolis or the Federal Reserve System. This paper is preliminary and is circulated to stimulate discussion. It is not to be quoted without the author's permission. 
This paper provides a simple counterexample to the standard belief that policy cooperation among benevolent governments is desirable. It also explains the circumstances under which such a counterexample is possible. In particular, consider a world economy in which governments choose economic policies to maximize the utility of the consumers in their countries. Suppose two distinct policy regimes are possible: either governments cooperate to set policies or they play a noncooperative game. Intuitively, consumers would seem to be at least as well of $f$ when governments cooperate as when they do not. However, this is not necessarily true.

That result may be puzzling. Indeed, one may imagine it is trivial to show that the opposite conclusion is true, namely that the outcome under cooperation must always be at least as desirable as that under noncooperation. After all, one might think, cooperating policymakers can always implement the noncooperative outcome simply by choosing their noncooperative strategies. And since that outcome is feasible under cooperation, rational policymakers will never choose something worse. Therefore, the cooperative outcome will always be at least as desirable as the noncooperative.

Although intuitively appealing, this simple argument is fallacious. The error is the implicit assumption that the relation between government strategies (policies) and outcomes (equilibrium allocations) does not vary across regimes. In general, as the regimes change, so do the strategies of private agents, who are also players in the game. Since the equilibrium outcome depends on the strategies of both the governments and the private agents, as the agents' strategies change so does the relation between government strategies and outcomes. Under such circumstances, there is no a priori reason to believe that cooperation among governments can or will improve matters. 
In the paper we demonstrate the undesirable cooperation result with a two country version of Fischer's (1980) optimal tax model. In order to understand this result it is useful to review Fischer's model ${ }^{1}$ and results. His model is a simple two period closed economy model with two goods, (labor and a produced good) a government and a large number of identical consumers. In the first period consumers have a given endowment of the produced good. Out of this they consume some and then save the rest in the form of capital. In the second period they decide how much labor to supply and then spend all of their capital and labor income on consumption of the produced good. The government faces an optimal tax problem: choose the tax rates on capital and labor income to finance a given amount of government spending. This tax problem is optimal in the sense that the government maximizes the welfare of the representative consumer.

Fischer considers two versions of this environment: one with a commitment, technology and one without one. In the first, this technology makes it feasible for governments to commit to specified tax rates at the beginning of the first period. From the point of view of a government in this environment--a government that commits its tax rates before consumers make either of them decisions--both capital and labor are elastic with respect to the tax rates it sets. For standard elasticity reasons, the optimal way to finance government spending is to set nonzero tax rates on both capital and labor.

In the other environment where there is no such commitment technology the government is free to choose new tax rates after consumers make their savings decisions. From the point of view of such a government, because these savings decisions have already been made, savings is completely inelastic with respect to tax rates. However, since the labor supply decisions have yet to 
be made they are elastic with respect to tax rates. In this environment, for standard elasticity reasons, it is optimal to tax capital income and try to avoid taxing labor. Of course, if government spending is larger than the capital income, capital will be taxed at rate one and the labor will be taxed as much as is needed to finance the rest of spending.

We consider a two country version of this model. The key assumptions are that capital is mobile (in the sense that consumers are free to invest their savings in either country) while labor is immobile. We consider two regimes: one in which governments cooperatively set tax rates to maximize world welfare and another in which they play a Nash game against each other. It is easy to show that if there were a commitment technology then the cooperative regime would be preferred by all (both governments and all the private agents) to the noncooperative regime. However, as this paper shows, without such a technology the opposite may be true; namely, the noncooperative regime may be preferred by all.

Absent a technology for commitment governments are free to set new tax rates after consumer's make their first period consumption decisions. We assume that after these rates are set capital can flee to whichever country offers the higher rate of return. In this setup the cooperative regime is identical to Fischer's. Each government sets a confiscatory rate on capital. In equilibrium consumers end up saving zero and all the tax revenues are raised from labor. However, in the noncooperative regime governments undercut each others capital tax rates in an attempt to attract foreign capital. Given the separable production function technology assumed, there is no incentive to subsidize capital and the Nash tax rates are zero. It is then easy to show that cooperation among these benevolent governments is undesirable. 
This paper is related to the seminal work of Rogoff [1985]. Rogoff constructs a two country version of the Kydland-Prescott [1977] inflationunemployment example. In the model private agents are summarized by demand functions of a Mundell-Fleming variety. Added to these demand functions are separate social loss functions for the central banks. Using this model he shows central banks cooperating to set monetary policy leads to a lower value of their social loss function then noncooperating does.

We argue the result in this paper is actualiy quite different from Rogoff's. In particular, the time inconsistency of the Kydland-Prescott inflation example and Rogoff's two country version of it depends entirely on the fact that the government is not maximizing the welfare of its residents. If this malevolent government is made benevolent then the problem disappears. Indeed a model with the government playing a game against the private sector is simply a dynamic game with two types of agents with conflicting interests. In such a case the so-called time inconsistency problem is just a restatement of the Simaan and Cruz [1973] result that in such dynamic games the timing of moves matters. As we argue in section 6 and in Chari, Kehoe, and Prescott [1987] the type of time inconsistency that arises in these malevolent government models is different from the type that arises in the benevolent government models of say Kydland-Prescott [1980], Fischer [1980], LucasStokey [1980], and Sargent [1987]. In particular, this latter type of time consistency "probiem" simply reflects the fact that, absent a commitment technology, there are natural dynamic incentive constraints that are part of the dynamic optimal tax problem.

This paper makes two contributions to the literature. First, it demonstrates the undesirable cooperation result in a fully-specified model. Second, it shows that this result does not depend solely on the fact that governments are playing a game against their own residents. 
The paper is organized as follows. Section 1 describes the world economy. Section 2 analyses government policies in the cooperative and noncooperative regimes. Section 3 characterizes equilibria of these regimes. Section 4 discusses uniqueness of equilibrium in the two regimes. Section 5 discusses the assumptions of the model and section 6 relates this paper to the literature. Section 7 concludes.

\section{The World Economy}

Consider a two-period symmetric world economy consisting of a home country and a foreign country, denoted by $i=h$ and $f$, respectively. Each country is populated by a large number of identical consumers and a government. Each country has access to the same linear production function for which the marginal products of labor and capital are denoted by the constants $\mathrm{W}$ and R, respectively. For simplicity, assume (somewhat as Fischer [1980] does) that consumers have consumption-savings-investment decisions in the first period and consumption-labor supply decisions in the second. In particular, in the first period consumers in country $i$ are each endowed with $y$ units of the consumption good out of which they each consume $c_{1}^{i}$ and save $s^{i}$. The consumer then invests some savings, $\mathrm{k}_{\mathrm{h}}^{i}$, in the home country and the rest, $k_{f}^{i}$, in the foreign country. In the second period the individual consumes $c_{\frac{1}{2}}^{\frac{1}{2}}$ units of the consumption good and $\bar{n}-n^{i}$ units of leisure out of a total income of $\left(1-\theta_{h}\right) R k_{h}^{i}+\left(1-\theta_{f}\right) R k_{f}^{i}+\left(1-\tau_{i}\right) w n^{i}$. Here $\bar{n}$ is the endowment of labor, $\theta_{h}$ and $\theta_{f}$ are the tax rates on capital in the home and foreign countries, and $\tau_{i}$ is the tax rate on labor in country $i$. Assume that savings is completely and costlessly mobile between countries and that labor is immobile. A consumer in country i chooses $\left\{c_{1}^{i}, s^{i}, k_{h}^{i}, k_{f}^{i} ; c_{2}^{i}, n^{i}\right\}$ to solve

(1.1) $\quad \max \left[U\left(c_{1}^{i}\right)+B U\left(c_{2}^{i}, \bar{n}-n^{i}\right)\right]$ 
subject to

$$
\begin{aligned}
& c_{1}^{i} \leq y-s^{i} \\
& k_{h}^{i}+k_{f}^{i} \leq s^{i} \\
& c_{2}^{i} \leq\left(1-\theta_{h}\right) R k_{h}^{i}+\left(1-\theta_{f}\right) R k_{f}^{i}+\left(1-\tau_{i}\right) w n^{i}
\end{aligned}
$$

where $U\left(c_{1}^{i}\right)$ and $U\left(c_{2}^{i}, \bar{n}-n^{i}\right)$ are both strictly monotone, concave, smooth and satisfy the usual Inada conditions.

The government of country i sets proportional tax rates on capital income, $\theta_{i}$, and labor income, $\tau_{i}$, in order to finance second-period per capita government spending, $g$, which is exogenously given. Let $\pi_{i}=\left(\theta_{i}, \tau_{i}\right)$ denote the tax policy of country $i$ and let $\pi=\left(\pi_{h}, \pi_{f}\right)$ denote the vector of such policies. Each government has monopoly rights to tax all capital and labor income earned within its borders. In particular, each government can earn tax revenue from the investment of foreigners. The budget constraint of government i is

$$
\text { (1.2) } g \leq \theta_{i} R\left(k_{i}^{h}+k_{i}^{f}\right)+\tau_{i} w n^{i} \text {. }
$$

Each government $i$ faces an optimal taxation problem: choose tax rates $\pi_{i}$ to maximize the welfare of a representative consumer of its country, subject to the budget constraint $(1.2)$. 
Events in the model are timed this way:

In period 1:

In period 2:

1. Consumers decide how much to consume and save.

2. Governments set tax rates.

3. Consumers decide in which country to invest.
1. Consumers decide how much to consume and work.

2. Governments collect tax revenues.

As discussed in the introduction this timing convention is a simple way to introduce the possibility of "capital" flight. That is, under this timing savings will flee the country that taxes capital income too highly.

It will prove convenient to express the consumers problem as a two stage problem. Since the consumer's budget constraints will bind with equality we can substitute them out and write the home consumer's problem as

$$
\text { (1.3) } \max _{\left\{s^{h}\right\}}\left[U\left(y-s^{h}\right)+B V^{h}\left(s^{h}, \pi\right)\right]
$$

where

$$
V^{h}\left(s^{h}, \pi\right)=\max _{k_{h}^{h}, n^{h}} U\left(\left(1-\theta_{h}\right) R k_{h}^{h}+\left(1-\theta_{f}\right) R\left(s-k_{h}^{h}\right)+\left(1-\tau^{h}\right) w n^{h}, \bar{n}-n^{h}\right)
$$

This problem defines the home consumer's optimal policy for savings, home investment and labor supply which we denote by $S^{h}(\pi), K_{h}^{h}\left(s^{h}, \pi\right)$ and $N^{h}\left(s^{h}, \pi\right)$, respectively. Using the budget constraints we can use these to obtain the optimal policies for consumption $C_{1}^{h}(\pi), C_{2}^{h}\left(s^{h}, \pi\right)$ and foreign investment $\mathrm{K}_{\mathrm{f}}^{\mathrm{h}}\left(\mathrm{s}^{\mathrm{h}}, \pi\right)$. Notice that our notation allows these policies to depend on all four tax parameters $\pi=\left(\theta_{h}, \tau_{h} ; \theta_{f}, \tau_{f}\right)$. However, since labor is immobile these functions do not vary with the foreign tax on labor. Also, since 
savings is mobile consumers will invest all of their savings in the country with the higher after tax rate of return and thus the lower tax rate on capital income. Assume that if the aftertax returns in the countries are equal, consumers invest all their savings in their own country. The problem and optimal policies for a representative consumer in the foreign country are symmetric.

Consider next the problem of the home government. The objective function of this government is $w^{h}\left(s^{h}, \pi\right)$ where

$$
w^{h}\left(s^{h}, \pi\right)=U\left(y-s^{h}\right)+B U\left(C_{2}^{h}\left(s^{h}, \pi\right), \bar{n}-N^{h}\left(s^{h}, \pi\right)\right) .
$$

The budget constraint of the home government is

$$
\text { (1.6) } \quad g \leq \theta_{h} R\left(K_{h}^{h}\left(s^{h}, \pi\right)+K_{h}^{f}\left(s^{f}, \pi\right)\right)+\tau_{h} w N^{h}\left(s^{h}, \pi\right)
$$

where $\mathrm{K}_{\mathrm{h}}^{\mathrm{f}}\left(\mathrm{s}^{\mathrm{f}}, \pi\right)$ denotes the foreign consumers' investment in the home country.

Finally we make two assumptions that will greatly simplify the computation of equilibrium and the comparison of welfare levels in the two regimes. First we assume

(1.7) $\quad \mathrm{g} \geq \mathrm{Ry}$.

This condition will turn out to guarantee that in any equilibrium it is always necessary to tax labor. Second, we will assume that it is always feasible for governments to finance their spending solely through a labor tax. In Kehoe [1985] we analyzed the case in which these conditions do not hold. We showed the same results go through in that case, however, the computation of equilibrium is substantially more complicated and required numerical simulations. 


\section{Tax Policy}

In this section the government tax policies in the two regimes are characterized. We show that the tax rate on capital is equal to one in the cooperative regime and equal to zero in the noncooperative regime. The labor taxes in the two regimes then solve, for each level of savings, certain constrained optimal tax problems. We will use these results in section 3 to characterize the equilibria of the two regimes.

\subsection{Cooperative}

Consider first the regime in which countries set tax rates cooperatively. In particular, imagine that the two governments set tax rates to maximize the sum of their objective functions subject to their budget constraints. In order to keep the analysis simple we will concentrate on symmetric equilibria. (For an analysis of the type of complications that arise with asymmetric cooperative equilibria see Chari-Kehoe [1986].)

At the time the tax rates are set the savings decisions by consumers already have been made. The tax policies of the governments will thus be functions of these savings levels. Of course, when the tax rates are equal, home savings will equal foreign savings, all the home savings will be invested in the home country, are all foreign savings will in the foreign country. The problem then resembles that of two closed economies. The superscripts and subscripts can be dropped and each government's problem written as follows: taking as given the current state $(s, s)$ and the policy functions of consumers, choose tax schedules $\theta(s, s)$ and $\tau(s, s)$ to solve

(2.1) $\quad \max W(s, \pi)$ 
subject to

$g \leq \theta R s+\tau \omega N(s, \pi)$.

The policy functions $\hat{\pi}(s, s)=(\hat{\theta}(s, s), \hat{\tau}(s, s))$ that solve (2.1) will be called the cooperative tax policies. Using the logic of Fischer [1980] and standard techniques in public finance we can show these tax rates are as follows:

Proposition 1. (Characterization of the cooperative tax policies.) The cooperative tax rates on capital are identically equal to zero. For each s, the cooperative tax rate on labor is given in the solution to: choose $c_{2}, n$, $\tau$ to solve

(2.2) $\quad \max U\left(c_{2}, \bar{n}-n\right)$

subject to

(2.3) $\quad c_{2} \leq(1-\tau)$ wn

(2.4) $\frac{\mathrm{U}_{2}}{\mathrm{U}_{1}}=(1-\tau)$

(2.5) $\mathrm{g} \leq \mathrm{Rs}+(1-\tau) \mathrm{Wn}$.

Proof. Since savings is already given it is completely inelastic with respect to the tax on capital. However, at the time tax rates are set the labor supply decision has yet to be made and so labor supply is distorted by the labor tax. To minimize distortions governments raise as much revenue as they can from the taxation of savings. From our assumption (1.4), that $\mathrm{g}$ is greater than Ry, it follows that even if all the endowment is saved arid taxed away completely revenues from this tax are less than government spending. Thus the tax on capital is identically equal to one. 
Next, for each savings level $s$ the cooperative labor tax $\tau$ is given in the solution to the problem in the proposition. The idea is to first impose the constraint that the capital tax is identically one and then use the standard public finance technique of writing out the conditions that define the consumer's policy functions as constraints on a maximization problem in which both tax policies and consumer policies are chosen.

In particular, in any cooperative equilibrium $\hat{\theta}$ and $\hat{\tau}$ maximize $W(s, \pi)$ subject the government budget constraint. Since we know $\hat{\theta}=1$ we can substitute this in and maximize with respect to $\tau$. Next, since savings is fixed and utility is time separable we can drop first period utility. Thus, in any cooperative equilibrium the labor tax $\tau$ must solve

$$
\text { (2.6) } \quad \max U\left(C_{2}(s, \pi), \bar{n}-N(s, \pi)\right)
$$

subject to

$$
g \leq R S+(1-\tau) w N(s, \pi) .
$$

Notice that since labor is immobile home consumers policies do not depend on the foreign labor tax and vice versa. Thus, (2.6) is identical to an optimal tax problem of a closed economy with its capital tax constrained to equal one. Now in the problem (2.6) the consumer's policy functions $C_{2}(\cdot)$ and $N(\cdot)$ are the solutions to $(1.4)$. With the capital tax equal to one the consumers problem $(1.4)$ reduces to

$$
\max U\left(c_{2}, \bar{n}-n\right)
$$

subject to $c_{2}=(1-\tau)$ wn. 
Writing the first order conditions on this problem as constraints on the government's tax problem (2.6) yields maximization problem stated in the proposition. $\diamond$

\subsection{Noncooperative}

Consider next the regime in which governments set tax rates noncooperatively. Governments set tax policies as functions of the level of savings in both countries $s^{h}$ and $s^{f}$. Denote these policies $\theta_{h}\left(s^{h}, s^{f}\right)$ and $\tau_{h}\left(s^{h}, s^{f}\right)$ for the home country and $\theta_{f}\left(s^{h}, s^{f}\right)$ and $\tau_{f}\left(s^{h}, s^{f}\right)$ for the foreign country. When making its decision, the home government takes as given these savings levels, the policy functions of the consumers, and the policy functions of the foreign government. Thus, the home government chooses tax policy $\pi_{h}=\left(\theta_{h}, \tau_{h}\right)$ as functions of the savings levels, to maximize

$$
W^{h}\left(s^{h}, \pi_{h}, \pi_{f}\left(s^{h}, s^{f}\right)\right)
$$

subject to

$$
g \leq \theta_{h} R\left(K_{h}^{h}+K_{h}^{f}\right)+\tau_{h} w^{h}
$$

where it is assumed that $\theta_{h}$ and $\tau_{h}$ lie in $[-1,1]$. The problem of the foreign country is symmetric.

In this noncooperative regime the Nash tax policies are a vector of policy functions $\left(\pi_{h}^{*}\left(s^{h}, s^{f}\right), \pi_{f}^{*}\left(s^{h}, s^{f}\right)\right)$ that satisfy each government's budget constraint and

$$
w^{h}\left(s^{h}, \pi_{h}^{*}\left(s^{h}, s^{f}\right), \pi_{f}^{*}\left(s^{h}, s^{f}\right)\right) \geq W^{h}\left(s^{h}, \pi_{h}, \pi_{f}^{*}\left(s^{h}, s^{f}\right)\right)
$$

for all $\pi_{h}$ that satisfy the home government's budget constraint, and 
(2.11) $\quad W^{f}\left(s^{h}, \pi_{h}^{*}\left(s^{h}, s^{f}\right), \pi_{f}^{*}\left(s^{h}, s^{f}\right)\right) \geq W^{f}\left(s^{f}, \pi_{h}^{*}\left(s^{h}, s^{f}\right), \pi_{f}\right)$

for all $\pi_{f}$ that satisfy the foreign government's budget conscraint.

We can characterize the Nash tax policies in a manner similar to that in Proposition 1. In particular, we have

Proposition 2. (Characterization of the Nash tax policies.) The Nash tax rates on capital are identically equal to zero. For each $s^{i}$ the tax rate on labor $\tau^{i}$ is given in the solution to the problem: choose $c_{2}^{i}, n^{i}$, and $\tau^{i}$ to solve

(2.12) $\max U\left(c_{2}^{i}, \bar{n}-n^{i}\right)$

subject to

(2.13) $\quad c_{2}^{i}=R s^{i}+\left(1-\tau^{i}\right)_{W n}{ }^{i}$

(2.14) $\quad \frac{U_{1}^{i}}{U_{2}^{i}}=\left(1-\tau^{i}\right)$

(2.15) $g \leq \tau^{i} n^{i}$.

Proof. First we show that in any Nash equilibrium the tax rates on capital on identically equal to zero. Clearly these tax rates cannot be positive. If both are then at least one of the governments could cuts its rates, attract all the world's savings, and make itself strictly better off. If only one of the governments sets a positive rate then that government can make itself strictly better off by lowering its rate. Likewise, these tax rates cannot be negative. If either government is subsidizing capital it can lose less revenue by cutting its subsidy. Since the marginal product of labor is constant cutting the subsidy makes this country strictly better off. Finally, if one 
government sets its tax rate on capital identically equal to zero, the other government is indifferent among all possible policies for taxing capital, including the policy in which the tax rate is identically zero. Such a policy is always feasible since we have assumed that each country can finance its spending solely through a labor tax.

Next, we show for each saving level $s^{i}$, the Nash labor tax $\tau^{i}$ is given in the solution to the problem in the proposition. The proof of this is nearly identical to that for the cooperative labor tax. The only difference is that here we impose as a constraint that the tax on capital equals zero. Since the foreign labor tax does not enter into the home consumer's policies the rest of the proof follows Proposition 1.8

\section{Equilibrium}

In section 1 the consumer's maximization problems were defined. In section 2 the cooperative and noncooperative tax policies were characterized. In this section we define the equilibrium in the two regimes and we characterize them as solutions to certain constrained optimal taxation problems. We then compare welfare in the two regimes and give sufficient conditions for welfare in a noncooperative equilibrium to be strictly higher than the welfare of the cooperative equilibrium.

\subsection{Cooperative}

An equilibrium in the cooperative regime is called a perfect cooperative equilibrium $^{2}$ and is defined as a set of consumption levels $\left(c_{1}^{i}, c_{2}^{i}\right)$, labor supplies $n^{i}$, savings levels $s^{i}$, investment levels $\left(k_{n}^{i}, k_{f}^{i}\right)$ and tax rates $\pi_{i}=\left(\theta_{i}, \tau_{i}\right)$, for $i=h$, f such that 
- Consumer maximization. Taking $\pi_{h}$ and $\pi_{f}$ as given the allocation $\left(c_{1}^{i}, c_{2}^{i}, n^{i}, s^{i}, k_{h}^{i}, k_{f}^{i}\right)$ solves the consumer's problem $(1.3)$ for $i=h, f$.

- Cooperative equilibrium for governments. The tax rates $\pi_{i}$ satisfy $\pi_{i}=$ $\hat{\pi}_{i}\left(s^{h}, s^{f}\right)$ for $i=h, f$, where the $\hat{\pi}_{i}(\cdot)$ denote the cooperative tax policies.

We can show that the solution to an optimal tax problem in which the tax rates on capital are constrained to equal one and the savings levels are constrained to equal zero is a cooperative equilibrium. In particular, we have

- Proposition 3. (Characterization of a perfect cooperative equilibrium.) A solution to the following optimal taxation problem is a perfect cooperative equilibrium, choose $c_{1}^{i}, c_{2}^{i}, n^{i}$, and $\tau^{i}$ to solve

$$
\max U\left(c_{1}^{i}\right)+B U\left(c_{2}^{i}, \bar{n}-n^{i}\right)
$$

subject to

$$
\begin{aligned}
& c_{1}^{i} \leq y \\
& c_{2}^{i} \leq\left(1-\tau^{i}\right) \mathrm{wn}^{i} \\
& \frac{U_{1}}{U_{2}}=\left(1-\tau^{i}\right) \\
& g \leq \tau{ }^{i}{ }^{i}
\end{aligned}
$$

and let the tax rates on capital $\theta^{i}$ be equal to one, and let the savings and investment levels be equal to zero.

Proof. We can combine the definition of a perfect cooperative equilibrium, Proposition 1 and the consumer's problem (1.3) to give the result. From 
Proposition 1 we know that in any cooperative equilibrium $\theta_{h}=\theta_{f}=1$. This implies the equilibrium reduces to two closed economy tax problems in which the tax on capital is constrained to equal one. Moreover, since first period utility function is strictly increasing any consumer faced with a confiscatory tax on capital will necessarily save and invest zero. We can then impose these conditions as constraints on the optimal tax problem. The solution to this problem is thus a cooperative equilibrium. $\diamond$

\subsection{Noncooperative}

An equilibrium in the noncooperative regime is called a perfect Nash equilibrium and is defined as a set of consumption levels $\left(c_{1}^{i}, c_{2}^{i}\right)$, labor supplies $n^{i}$ savings levels $s^{i}$, investment levels $\left(k_{h}^{i}, k_{f}^{i}\right)$ and tax rates $\pi_{i}$ $=\left(\theta_{i}, \tau_{i}\right)$ for $i=h$, f such that

- Consumer maximization. Taking $\pi_{h}$ and $\pi_{f}$ as given the allocation $\left(c_{1}^{i}, c_{2}^{i}, n^{i}, s^{i}, k_{h}^{i}, k_{f}^{i}\right)$ solves the consumer's problem $(1.3)$ for $i=h, f$.

- Nash equilibrium for governments. The tax rates $\pi_{i}$ satisfy $\pi_{i}=\pi_{i}^{*}\left(s^{h}, s^{f}\right)$ for $i=h, f$, where the $\pi_{i}^{*}(\cdot)$ denote the Nash tax policies.

We can show that the solution to an optimal tax problem in which the tax rates on capital are constrained to equal zero is a perfect Nash equilibrium.

Proposition 4. (Characterization of a perfect Nash equilibrium.) A solution to the following optimal taxation problem is a perfect Nash equilibrium: choose $c_{1}^{i}, c_{2}^{i}, n^{i}, s^{i}$, and $\tau^{i}$ to solve

$$
\max U\left(c_{1}^{i}\right)+\beta U\left(c_{2}^{i}, \bar{n}-n^{i}\right)
$$

subject to 


$$
\begin{aligned}
& c_{1}^{i} \leq y-s^{i} \\
& c_{2}^{i} \leq R s^{i}+\left(1-\tau^{i}\right) w n^{i} \\
& \frac{U_{1}}{U_{2}}=\left(1-\tau^{i}\right) \\
& g \leq \tau w n
\end{aligned}
$$

and let the tax rates on capital $\theta^{i}$ be equal to zero and let the investment levels be $k_{i}^{i}=s^{i}$ and $k_{j}^{i}=0$ and $j \neq i$.

Proof. If we combine the definition of a perfect Nash equilibrium with Proposition 2 and the consumers problem (1.3) then this result is almost immediate. From Proposition 2 we know that in any Nash equilibrium $\theta_{h}=\theta_{f}=0$. In particular this implies the tax rates on capital be equal and so all of country i's savings is invested in country i. Next, since the foreign country's tax on labor does not enter into home consumer's problem, and vice versa, the equilibrium reduces to two closed economy tax problems in which the tax on capital is constrained to be zero. Finally, notice that since this capital tax is zero we do not need to include the first order condition for savings as a constraint in this problem. The solution to this tax problem is thus a perfect Nash equilibrium. $\diamond$

\subsection{Welfare comparisons}

In propositions 3 and 4 we show that the solutions to certain optimal taxation problems are cooperative and noncooperative equilibria, respectively. It is easy to show that the cooperative equilibrium is unique and thus Proposition 3 completely characterizes the cooperative equilibrium. Absent further restrictions, however, there may be multiple Nash equilibria. 
In this case Proposition 4 characterizes the Nash equilibrium with the highest level of welfare. Since the main purpose of this paper is to provide a counterexample, it is not necessary to characterize all the Nash equilibria, rather it is only necessary to show there is at least one Nash equilibrium which is strictly better than the cooperative equilibrium. Nonetheless, the economics behind the multiple Nash equilibrium is somewhat interesting in its own right and so we briefly consider the possible nonuniqueness of the Nash equilibrium in the section 4 and we prove that the cooperative equilibrium is unique.

We can use Propositions 3 and 4 to rank welfare levels of the cooperative and noncooperative equilibria. Notice that the cooperative equilibrium tax problem (3.1) is simply the Nash equilibrium tax problem (3.2) together with the constraint that savings must be zero. Thus, the welfare level in the Nash tax problem is greater than or equal to the welfare level in the cooperative problem. It is strictly greater as long as the allocations in the two problems are different, that is, as long as savings is not zero in the Nash equilibrium. A necessary and sufficient condition for the Nash allocation to be strictly preferred is that at the cooperative allocation

$$
\frac{U^{\prime}\left(\hat{c}_{1}\right)}{U_{1}\left(\hat{c}_{2}, \bar{n}-\hat{n}\right)}<R 8
$$

holds, where from the cooperative maximization problem, $\hat{c}_{1}=y$ and $\hat{c}_{2}=$ wn $-g$.

4. Uniqueness of Equilibrium

The main point of this paper is to present a fully specified environment with benevolent governments in which a cooperative equilibrium could be strictly worse than a noncooperative equilibrium. This was accomplished in 
section 3. In this section separate issues relating to the uniqueness of equilibrium in the two regimes are considered. We believe this analysis is of independent interest for two reasons. First, the type of nonuniqueness of perfect Nash equilibria that can arise here is completely different from the standard type of nonuniqueness that arises from trigger strategies in a infinite horizon game. Rather it arises from the government's inability to commit together with the fact that private agents are all "small" in the sense that they take government policies as given. If we changed either of these features, by introducing a commitment technology or by letting private agents not be policy takers, then this type of nonuniqueness would disappear. Second, this type of nonuniqueness seems to be a rather general feature of dynamic policy games that arises in a wide variety of models. Indeed, one of the few examples where it cannot arise is in the popular a linear-quadratic-game framework (with no budget constraints for the government).

For the cooperative regime it is easy to show the equilibrium is unique. Given the symmetry of the model we need only consider the home country. For convenience, let $\hat{S}(\tau)$ denote the domestic consumer's savings policy in the cooperative equilibrium as a function of the domestic tax on labor. That is, substitute into the savings function $S^{h}(\pi)$ the fact that tax rates on capital are one, and suppress the foreign labor tax, so $\hat{S}(\tau)=S^{h}(\pi)$ where $\pi=$ $\left(\theta_{h}, \tau_{h}, \theta_{f}, \tau_{f}\right)=(0, \tau, 0,0)$. Also, let $\hat{\tau}(s)$ denote the cooperative tax on labor as a function of the domestic savings rate which is characterized in proposition 1. Any equilibrium in the cooperative regime is any $(s, \tau)$ pair such that (4.1) $\hat{S}(\tau)=s$ and $\hat{\tau}(S)=\tau$.

Given $(s, \tau)$ the rest of the equilibrium allocations can be obtained by substituting this pair into the policy functions. Notice, however, in the coopera- 
tive regime the function $\hat{S}(\tau)$ is identically zero and so (4.1) has a unique solution namely $(0, \hat{\tau}(0))$. Thus, the cooperative equilibrium is unique.

For the noncooperative regime let $S^{*}(\tau)=S^{h}(\tau)$ with $\pi=(1, \tau, 1,0)$ and let $\tau^{*}(s)$ denote the Nash tax on labor characterized in Proposition 2 . A perfect Nash equilibrium is any $(s, \tau)$ pair such that

(4.2) $S^{*}(\tau)=s$ and $\tau^{*}(s)=\tau$.

For arbitrary utility functions there can be multiple solutions to (4.2) as for example in figure 1. (This is the type of figure that arises with the log utility example of Kehoe [1986]).

The intuitive idea behind these multiple equilibria is that these is a coordination problem among private agents. To see this suppose in figure 1 the high savings-high tax equilibrium $\left(s_{2}, \tau_{2}\right)$ is preferred to the low savings--low tax equilibrium $\left(s_{1}, \tau_{1}\right)$. If private agents could coordinate their savings decisions they could all choose the "good" Nash equilibrium $\left(s_{2}, \tau_{2}\right)$. However, we have explicitly assumed these agents don't coordinate. In particular, there are a large number of private agents that take as given the policies of all other agents as well as the tax policy of the government. Since each individual's savings depends only on the tax policy of the government $\tau(\cdot)$, and not directly on other agent's savings decisions, this is equivalent to taking the governments tax rate as given. If all other consumers happen to choose the high savings level then it is optimal for any one consumer to do so also. The government then ends up facing the high savings level and chooses the high tax rate. However, if all other consumers happen to choose the low level then its optimal for any one consumer to. The government ends up facing the low savings level and it is optimal for it to choose the low tax rate. Notice that it is not even feasible for a government facing 
the low ("bad") savings level to choose the high ("good") tax rate. The optimal tax problem in Proposition 4 picks out the good Nash equilibrium.

If one wanted to rule out these multiple Nash equilibrium one could do so by restricting utility functions to be such that these curves $\tau(\cdot)$ and $S^{*}(\cdot)$ intersect only once in the relevant region. For example, one could assume utility functions were such that one of these curves had an everywhere steeper slope than the other one.

\section{Discussion of Assumptions}

The goal of this paper is to give a counterexample to a standard belief. For this reason we constructed an extremely simple model for which the economic intuition was especially transparent. In doing so we made a variety of assumptions that kept the analysis simple. In this section we briefly discuss the role of some of these assumptions.

An assumption that proved particularly useful was that the production function was linear. It is easy to see that a nearly identical analysis would go through as long as the production function is separable in capital and labor. If we instead assume this function is nonseparable several parts of the analysis change. In the cooperative regime the tax rate on capital is still one but the level of welfare changes. Suppose that the marginal product of labor declines as the capital stock declines. If capital is essential for production, so that this marginal product declines to zero as the capital stock declines to zero, no equilibrium will exist. To avoid this we could assume there is some initial capital stock, say $\bar{k}$, that is untaxable. An equilibrium in the cooperative regime will have $k=\bar{k}$. Welfare in this regime will decrease as $\bar{k}$ is decreased.

The analysis in the noncooperative regime is also changed. Since capital increases the marginal product of labor each government has an incen- 
tive to subsidize capital and the Nash tax rates on capital will be negative. In equilibrium there will be an overabundance of capital. Thus with a nonseparable production function the levels of welfare in both regimes are changed. These levels depend on the shapes of utility function, production function and initial endowments. By choosing $\bar{k}$ appropriately we can construct examples in which cooperation is undesirable. However, if it was desired we could choose these functions so that cooperation is desirable and thus produce a counterexample to this counterexample.

Another assumption we made was that all the capital was mobile. Instead we could have let them be two types of capital some of which was stuck in its country and some of which was mobile. In the cooperative regime governments would tax both types of capital at the same rate. For a high level of government spending this rate would be one. In the noncooperative regime the government would tax the immobile capital at rate one and the mobile capital at rate zero. It is easy to construct a counterexample in this case, we would just have to carry around the extra notation.

Finally, in this paper it was assumed that there were two countries. It is easy to check, either directly or using the general approach of Chari and Kehoe (1987) that as the number of countries is increased both the noncooperative and cooperative allocations are unchanged.

\section{Relation to the Literature}

The model in this paper is a two country version of Eischer's [1980] optimal tax model. In a related paper Rogoff [1985] obtained results similar to those described have using a two country version of the Kydland-Prescott [1977] inflation-unemployment model. The main differences between Rogoff's paper and this paper stem directly from those between the Kydland-Prescott model and the Fischer model. One distinction between these models is that the 
Fischer model has explicit microfoundations while the Kydland-Prescott model does not. The key distinction, however, is that in Fischer's model there is a "benevolent" government that maximizes the welfare of the private agents while in Kydland-Prescott's model there is a "malevolent" government that does not.

Both of these models exhibit time inconsistency, however, they do so for quite different reasons. In the Kydland-Prescott model the reason is simply that the government is playing against the private sector in a dynamic game. In particular, this malevolent type of time inconsistency remains regardless of whether the government is playing against one large private agent or against a large number of small private agents. In either case this type of time inconsistency is simply a restatement of the Simaan and Cruz [1973] result that in dynamic games between players with different objective functions the timing of moves matters. Indeed it is easy to show that this type of time inconsistency disappears when government maximizes the we'lfare of the private agents.

The Fischer (1980) tax model, exhibits a second, more subtle, type of time inconsistency. In this model the conflict is not between the private agents and the government rather the conflict is between the private agents themselves. Essentially each private agent wants to free ride of the others by getting them to pay for the public good. A somewhat loose description of the problem is that in the first period each agent wants to pass off the burden of paying taxes into the others. Thus, each private agent wants the other private agents to save a lot so that the taxes he personally will end up paying in the next period will be smaller. If we take away this gaming among private agents, say, by letting there be only one private agent, then this second type of time inconsistency disappears. 
Rogoff's model and his results on counterproductive cooperation are driven by the first type of time inconsistency. It is easy to check that if we let his governments maximize the welfare of their residents then the counterexample is overturned and cooperation is always at least as desirable as noncooperation. In contrast, my model and results are driven by this second type of time consistency. In the cooperative regime each government is cooperating as best they can both with the other government and with the private agents. However, what drives my result is that in the competitive equilibrium private agents are not cooperating in the sense that they maximize their own utility. Thus while our papers are closely connected the logic behind the results is somewhat different.

Recently, I have come across a paper by Van der Ploeg [1986] which is related to both Rogoff's paper and this paper. In it, Van der Ploeg uses a two country version of Calvo's inflation tax example and explores the possibility of undesirable cooperation. However, for reasons that the author explains it is quite difficult to solve for perfect equilibria of the model. Instead he solves for some other type of equilibrium which he calls the "loss of leadership" equilibrium. However, as Van der Ploeg clearly points out this equilibrium is not subgame perfect and in it the private agents are effectively fooled by the government. Because of this feature it is difficult to relate this paper to my own. Of course, such a two country Calvo model has the ingredients necessary for a counterexample and so it may well turn out the subgame perfect equilibrium of such a model can produce counterproductive cooperation for reasons very similar to those analyzed here.

\section{Conclusion}

The main results in the paper are driven by a time inconsistency problem that arises even with benevolent governments. One interpretation of 
this type of "problem" is the following. Given a technology for commitment and a closed economy the relevant tax problem of the government is the static Ramsey problem. However, absent such a technology the relevant tax problem is this static problem together with dynamic incentive compatibility constraints. For this model these constraints require that the tax on capital be equal to one. In a two country world the cooperative regime has these same incentive constraints. However, in a noncooperative regime the competition among governments give rise to a different set of dynamic incentive constraints, namely that the tax on capital always be zero, and the resulting level of welfare may be higher. Loosely, the intuition for the result is that in a dynamic economy in which it is not feasible for governments to commit, competition among governments may act like partial commitment and hence may be preferred to cooperation.

One implication of the paper is the following. Consider a situation in which governments have no access to a commitment technology, are currently in a noncooperative regime, and are contemplating setting up a new institution through which governments can commit to cooperate. This paper shows that the value of such an institution may well be negative. Of course, it is possible to set up an institution through which governments can simultaneously guarantee both commitment and cooperation then they should do so and everyone would be better off.

Throughout the paper we have taken the choice of regime as institutionally determined. It would be an interesting research topic to analyze the choice of a regime in a strategic setting. In terms of this particular model we could consider a simple scenario in which the choice of cooperation of noncooperation is determined by the governments. In particular, suppose that after consumers make their savings decisions the two governments meet to 
decide on tax rates. For concreteness let one of the governments propose either the cooperative tax rates on the noncooperative tax rates, then let the other government decide to accept or reject the proposal. If it rejects then both governments play their noncooperative strategies. Interestingly, the unique subgame perfect equilibrium of this game is our cooperative regime. The reason is simple: for each level of savings both governments strictly prefer cooperation to noncooperation. Of course, in equilibrium consumers figure this out, do not save and everyone ends up not very well off. Thus, once we endogenize the choice of regime we introduce a type of time consistency problem in the regime itself. It may be interesting to pursue these ideas in a later paper.

Finally, although the model in the paper was constructed mainly to produce a counterexample, it is somewhat interesting in its own right. The model suggests that the possibility of capital flight in a strategic setting may make the analysis of taxation in an open economy drastically different from that in a closed economy. 
Notes

in Fischer [1980] government spending is an endogenously determined public good. Here government spending is exogenously given, and it yields no utility to private agents. For an analysis of optimal taxation in an open economy where government spending is a public good, see Chari and Kehoe [1987], Devereux [1986], and Kehoe [1987]. In related work Devereux [1986b] explores conditions under which cooperation by policymakers can lead to a time consistent equilibrium in an environment which shares several features with. the one considered here.

${ }^{2}$ The equilibria in this and the next section are called perfect because naturally embedded in the simple backward induction argument used to compute them is the notion of sequential rationality that is at the core of the concept of subgame perfect Nash equilibrium of extensive form games. The literature of game theory, macroeconomic theory, and control theory has a variety of equilibrium concepts which include the notion of sequential rationality; there does not seem to be a consensus on the most appropriate terminology. This paper's terminology seems to be the most popular. 
References

Chari, V. V. and Kehoe, Patrick J., (1986), "Coordination of Eiscal Policies in Limiting Economies," Research Department Working Paper 317. Minneapolis: Federal Reserve Bank of Minneapolis.

Devereux, Michael, (1986a), "International Coordination of Fiscal Policy and the Terms of Trade: An Example," mimeo. University of Toronto. , (1986b), "International Cooperation, Precommitment, and Welfare," mimeo. University of Toronto.

Fischer, Stanley, (1980), "Dynamic Inconsistency, Cooperation and the Benevolent Dissembling Government," Journal of Economic Dynamics and Control 2 (February): 93-107.

Kehoe, Patrick J., (1985), "International Policy Cooperation May Be Undesirable," Research Department Staff Report 103. Minneapolis: Federal Reserve Bank of Minneapolis.

, (1987), "Coordination of Fiscal Policies in a World Economy," Journal of Monetary Economics 19 (May): 349-76.

Kydland, Finn E. and Prescott, Edward C., (1977), "Rules Rather Than Discretion: The Inconsistency of Optimal Plans," Journal of Political Economy 85 (June): 473-91.

and , (1980), "Dynamic Optimal Taxation, Ra-

tional Expectations and Optimal Control," Journal of Economic Dynamics and Control 2 (February): 79-91.

Rogoff, Kenneth, (1985), "Can International Monetary Policy Cooperation be Counterproductive?," Journal of International Economics 18, no. 3/4 (May): $199-217$.

Van der Ploeg, F., (1985), "International Policy Coordination in Interdependent Monetary Economies," mimeo. The London School of Economics. 


$$
k
$$

